Family Medicine and Community Health

\title{
How French general practitioners adapt their care to patients with social difficulties?
}

\author{
Annie De Oliveira, ${ }^{1}$ Barbara Chavannes, ${ }^{1}$ Magali Steinecker, ${ }^{1}$ Mady Denantes, \\ Julie Chastang, ${ }^{1}$ Gladys Ibanez (D) ${ }^{1,2}$
}

To cite: De Oliveira A, Chavannes B, Steinecker M, et al. How French general practitioners adapt their care to patients with social difficulties? Fam Med Com Health 2019;7:e000044. doi:10.1136/ fmch-2018-000044

- Additional material is published online only. To view please visit the journal online (http://dx.doi.org/10.1136/fmch2018-000044).

Received 12 October 2018 Revised 03 September 2019 Accepted 09 September 2019

Check for updates

(C) Author(s) (or their employer(s)) 2019. Re-use permitted under CC BY-NC. No commercial re-use. See rights and permissions. Published by BMJ.

1'Department of General Practice Medicine Sorbonne University,

Paris, France

${ }^{2}$ Sorbonne Université, INSERM, Institut Pierre Louis d'Épidémiologie et de Santé Publique, (IPLESP), F75012,

Paris, France

Correspondence to Dr Gladys Ibanez, Department of general practice, Medicine Sorbonne University, Paris,

France; gladys.ibanez@yahoo.fr

\section{ABSTRACT}

Objective Several studies have shown the role of the primary care system in access to care and in reducing social inequalities in health. The objective of this study was to describe the practices of general practitioners (GPS) in taking into account the social environment of their patient, and the ways they adapted to social difficulties.

Design Qualitative study comprising interviews and focus groups.

Setting French primary care settings.

Participants Twenty semistructured interviews and two focus groups were conducted with $33 \mathrm{GPs}$. Sessions were audio recorded, transcribed verbatim and analysed using thematic analysis. The reporting of findings was guided by consolidated criteria for reporting qualitative research. Result This study identified adaptations at three levels: in the individual management of patients (alert system, full involvement in prevention, better communication, prioritised additional examinations, financial facilities, help in administrative tasks), in the collective management of patients in an office (consultation without appointment, pay-for-performance indicators, medical staffs, multidisciplinary protocols, medical practice in group, medical student), and in the community management (patients description, cooperation with associations, public health sector and politics).

Conclusion In France, GPs can take into account the social determinants of health in practice through simple or more complex actions.

\section{INTRODUCTION}

The distribution of health within countries follows a social gradient: people lower in the social hierarchy have lower life expectancy and higher risk of illness than those higher-up in the social hierarchy. ${ }^{1}$ The social gradient in health means that health inequities affect everyone. $^{2}$ One of the most important and underpinning principles of healthcare systems is based around the notion of equity, whereby healthcare services should be provided solely on the basis of clinical need. ${ }^{3}$

A consensus exists that health systems undergirded by primary healthcare principles achieve better health and greater equity in health than systems with a specialty care orientation. ${ }^{4-6}$ Primary care is the firstcontact, accessible, continued, comprehensive and coordinated care. The specificity of the general practitioner (GP) is that he/ she is: "the only clinician who operates at the nine levels of care: prevention, presymptomatic detection of disease, early diagnosis, diagnosis of established disease, management of disease, management of disease complications, rehabilitation, palliative care and counselling, ${ }^{7}$ In Europe, proportion of people who consulted a generalist medical practitioner during the four last weeks ranges from $15 \%$ to $55 \%$, depending on country and sex. ${ }^{8}$

Recent papers described the responsibility of public health teams for addressing social determinants. ${ }^{9-11}$ According to many national organisations, general practice may have a positive impact on health inequalities through clinical care, and community and political engagements. ${ }^{10}$ Moreover, several recommendations are rightly advocating social prescriptions as an important way to expand the options available for GPs to provide individualised care. ${ }^{13} 14$ A recent Canadian report recommends to act at the patient, practice and community levels with some specific measures (including the use of clinical flags, or patient's navigator) ${ }^{11}$ Recent changes in American and English healthcare policy have also presented opportunities for a paradigm shift in primary care delivery, including the integration of social determinants of health $(\mathrm{SDH})$ data into electronic health records. ${ }^{12} 131516$

Social and geographical disparities are more pronounced in France than in most other European countries. ${ }^{17} 18$ Tackling social health inequalities has become a priority for French social politics. Previous studies showed that $75 \%$ of French GPs report experiencing more difficulties in taking care of their patients with social difficulties than their other patients. ${ }^{1920}$ Financial 
access to care was described as a major obstacle, which doctors consider to be a political issue. Other difficulties included longer consultation time, communication problems, increased frequency of multimorbidity and so on. Casanova et al showed that French GPs tend to overestimate their patients' socioeconomic level. ${ }^{21}$ In this study, ideas for improvement in clinical practice were proposed in response to the obstacles, such as multidisciplinary networking or good relationship with patients. Then, some authors suggested ideas like identifying vulnerable people, taking into account patients' health literacy, promoting patient empowerment, developing cross-cultural skills and partnerships with medicosocial actors. ${ }^{22-24}$ To date, very few scientific studies have suggested actions to take into account the social difficulties of patients in GPs consultations. ${ }^{21}{ }^{25}$ A recent French recommendation has proposed collecting social data in medical records. ${ }^{26}$ The objective of this study was to describe the practices of GPs in taking into account the social environment of their patient, and the ways they adapted to social difficulties.

\section{METHODS}

\section{Sampling and recruitment}

The authors conducted 20 semistructured interviews and two focus groups with GPs. They were recruited using a combination of purposive and snowball sampling, in order to identify physicians working under different social conditions. Recruitment strategies and number of GPs recruited for this study were described in online supplementary file 1 . Interviews were carried out in the Paris region, between September 2015 and December 2018, a focus group took place in February 2017, and the last one in January 2018.

For the interviews, the only inclusion criterion was that the GP accepted to participate in the study. The interview lasted about 1 hour on average (range $25-85 \mathrm{~min}$ ). Three physicians refused to participate. No repeat interviews were carried out. Then, two focus groups were set up to provide the opportunity for building synergies as GPs listened to the views of each other and contributed with additional ideas. Six and seven participants were involved in each group. These GPs were recruited during a working seminar on networking healthcare. Each focus group lasted about 2 hours on average. No physicians refused to participate in the focus group discussions. We applied the Consolidated Criteria for Reporting Qualitative Research checklist to this qualitative study.

\section{Data collection}

The interview guide was initially developed by the research team, based on data in the literature and revised in consultation with individuals involved in guideline development. It was tested in three interviews with GPs before being used for the study and was then modified. All interviews and focus groups were conducted by one of the two authors: ADO (MD, female) or GI (MD, $\mathrm{PhD}$, female). The research team (GI, BC, MS, MD, JC) has previous experience in qualitative research, and the doctoral candidate (ADO) was trained in advance in qualitative research. At the beginning of each interview and focus group, the interviewer (ADO or GI) introduced herself, and provided information on the study. The main questions of the topic guide were described in online supplementary file 2 .

\section{Analysis}

The audio recordings from the interviews and focus groups were transcribed verbatim. The examination of transcripts was undertaken by the two interviewers and another doctoral medical student trained in qualitative analysis. The analysis was carried out based on thematic content and performed in four steps: first the text was read through several times in order to get to know the content. Then, open coding was performed on the transcripts to reach a consensus definition of categories and subcategories. Codes and categories were discussed among the co-researchers to allow themes to emerge based on constant comparison and interaction. Finally, all themes and theme categories were checked with the other authors to see whether new themes or theme categories were needed. The framework continually updated as the analysis progressed.

The study was explained to GPs who had the opportunity to ask any questions before a written consent was sought. Transcripts were not returned to participants for comment or correction. Data saturation was confirmed by two coders when no additional codes were identified. In accordance with the French Jardé law, it was not necessary to submit to an ethics committee a protocol for observational qualitative research involving health professionals. $^{27}$

\section{RESULTS}

Thirty-three GPs participated in total, with 20 being interviewed and 13 contributing to a focus group. The characteristics of GPs are summarised in table 1. There were 19 female and 14 male GPs. Participants declared having between $5 \%$ and $40 \%$ of their patients with social difficulties.

\section{Perception of GPs and the difficulties encountered}

For the GPs, the social context of a patient included four main components: housing situation; income and employment; family dynamics and social supports; access and quality of health and social care (details in table 2).

Focus 2: The social context is [...]: the patient in his house, his work, with his social relationships. Are there any difficulties in the patient's care pathway? Can the patient read? Can the patient pay for his care? [...].

There were three types of physicians regarding to patients' social categorisation: practitioners not sensitised; practitioners sensitised and attentive to the collection of 
Table 1 Characteristics of the general practitioners (GPs) included in the study $(n=33)$

\begin{tabular}{lc}
\hline Characteristics & Number of GPs \\
\hline Sex & 19 \\
\hline Female & 14 \\
\hline Male & \\
\hline Age & 6 \\
\hline <35 years & 16 \\
\hline $35-49$ years & 11 \\
\hline 50 years & \\
\hline Medical practice & 3 \\
\hline Alone & 30 \\
\hline Group practice & \\
\hline Medical secretariat & 20 \\
\hline Yes & 9 \\
\hline Yes, telesecretariat & 4 \\
\hline No & 13 \\
\hline Student patients & 10 \\
\hline Yes & \\
\hline of estimated patients with & \\
\hline social difficulties & \\
\hline 6-19 & \\
\hline $20-40$ & \\
\hline
\end{tabular}

Table 2 Main components of the patients 'social context'

\begin{tabular}{|c|c|}
\hline $\begin{array}{l}\text { Main components } \\
\text { of the patients } \\
\text { 'social context' }\end{array}$ & Description \\
\hline Housing situation & $\begin{array}{l}\text { Housing status } \\
\text { Indoor air quality (lead, mites, moulds) } \\
\text { Outdoor air quality (pollution, pollen, noise) } \\
\text { Accessibility to health services }\end{array}$ \\
\hline $\begin{array}{l}\text { Income and } \\
\text { employment }\end{array}$ & $\begin{array}{l}\text { Employment/profession } \\
\text { Socio-professional category } \\
\text { Occupational exposure } \\
\text { Work schedule (hours) } \\
\text { Perceived financial situation } \\
\text { Income (or type of social minimum income) } \\
\text { Immigration status } \\
\text { - Suffering at work }\end{array}$ \\
\hline $\begin{array}{l}\text { Family dynamics } \\
\text { and social supports }\end{array}$ & $\begin{array}{l}\text { Couple's relationship } \\
\text { Number of children } \\
\text { Presence of friends, people to rely on (in } \\
\text { case of disease), family referent (for elderly } \\
\text { people) } \\
\text { Physical, sexual or psychological violence } \\
\text { Beliefs influencing care }\end{array}$ \\
\hline $\begin{array}{l}\text { Access and quality } \\
\text { of health and social } \\
\text { care }\end{array}$ & $\begin{array}{l}\text { Renouncement to healthcare } \\
\text { Health literacy } \\
\text { Education level } \\
\text { Understanding of written French } \\
\text { Social coverage } \\
\text { Presence of a long duration disease } \\
\text { Presence of a referent general practitioner }\end{array}$ \\
\hline
\end{tabular}

social determinants data; practitioners sensitised and active in the collection of social determinants data.

\section{Practitioners not sensitised}

Unaccustomed to describing the social context of patients, they said they were not confronted to patients with social difficulties. They attributed this lack of awareness to the location of their office and to their agreement with the French Social Security system. They did not seek to collect data on patients' lifestyles.

Interviewee 3: "I do not ask questions [...]. It's not going to change my way of doing things! [...] but it's true that we're in a rather favoured neighbourhood so I do not really ask myself the question".

\section{Practitioners sensitised and attentive to the collection of social determinants data}

These physicians were mindful of the lifestyles of their patients and tried to take into account the social determinants into their care. They perceived the role of these determinants on health but were not involved in an active collection process. Often, they thought they knew the social environment of the patient from what they deduced, but did not ask direct questions and preferred to let the patients talk about these topics.

Interviewee 8: "It is important, the social and cultural context. Both are important. In practice, I don't systematically ask the question, because I think that it should be done gradually" [...]. "Sometimes, I do not realize it (eg, that patient may have financial difficulties) and then it's a catastrophe and I'm mad at myself".

Practitioners sensitised and active in the collection of social determinants data

These physicians were convinced of the role of social determinants on health. They take into account biological, psychological and social factors to adapt their care. They asked patients questions fairly systematically by explaining the reason for such data collection. Younger practitioners living in disadvantaged social areas or practicing in health centres (public structures) seemed to be particularly careful about the role of social determinants on health.

Interviewee 2: "We know that there are links between professions and diseases, between income and illness, between precariousness and illnesses, so yes, it is more than important!" [...] "It's pretty codified here: we ask a lot of questions from the first consultation ... we ask questions in a systematic way and we explain to the patient why we ask them".

\section{Feelings and practice of physicians when tackling patients' social difficulties}

The GPs raised many difficulties in caring for patients with social difficulties: in the biomedical approach (financial disincentives, difficulties in access to care or in the care pathway), in the psychosocial approaches (lack of training, complex situations), as well as in the administrative formalities (lack of time, language barriers). They 
Table 3 Ways GPs adapt to patients' social difficulties

\begin{tabular}{|c|c|c|}
\hline Levels of adaptation & Themes & Actions \\
\hline \multirow[t]{4}{*}{$\begin{array}{l}\text { In the individual } \\
\text { management of patients }\end{array}$} & Collect and screening & $\begin{array}{l}\text { Collect social data (subjective or objective criteria; home visits) } \\
\text { Full involvement in prevention } \\
\text { Adapt the duration of consultations to the patients' needs }\end{array}$ \\
\hline & $\begin{array}{l}\text { Developing electronic } \\
\text { health record }\end{array}$ & $\begin{array}{l}\text { Systematically collect social and preventive data } \\
\text { Red flags in medical records } \\
\text { Track social changes over time }\end{array}$ \\
\hline & Communication & $\begin{array}{l}\text { Adaptation of communication: simple terms, written documents, drawings, } \\
\text { different spoken languages } \\
\text { Evaluate health literacy } \\
\text { Call patients to ensure proper follow-up } \\
\text { Help make appointments for patients } \\
\text { Translators (family, other) }\end{array}$ \\
\hline & Training & GPs training (continuous professional development) \\
\hline \multirow[t]{2}{*}{$\begin{array}{l}\text { In the collective } \\
\text { management of patients }\end{array}$} & Access to care & $\begin{array}{l}\text { Consultation without appointment } \\
\text { Wide opening office hours } \\
\text { On-line appointments } \\
\text { Medical students in GP offices } \\
\text { Network of specialist colleagues who do not charge higher consultation rates }\end{array}$ \\
\hline & Care pathway & $\begin{array}{l}\text { Facilitating the care pathway of patients (medical practice in group, including } \\
\text { multidisciplinary healthcare homes) } \\
\text { Posting of written information and pamphlets in the waiting room } \\
\text { Multidisciplinary consultative meetings of health professionals } \\
\text { Multidisciplinary protocols for medical offices } \\
\text { Therapeutic support groups } \\
\text { Telemedicine }\end{array}$ \\
\hline \multirow{2}{*}{$\begin{array}{l}\text { In the community } \\
\text { management }\end{array}$} & $\begin{array}{l}\text { Coordination of care and } \\
\text { collaborations }\end{array}$ & $\begin{array}{l}\text { Coordination of care with other sociomedical professionals (other specialists, } \\
\text { social workers) } \\
\text { Collaborations with public health services } \\
\text { Collaborations with associations, key persons in the community }\end{array}$ \\
\hline & Public authorities & Collaborations with public authorities \\
\hline
\end{tabular}

GP, general practitioner.

developed strategies to adapt to the social difficulties of their patients at three levels (table 3).

\section{Adaptation strategies for individualised patient management}

In order to identify patients at risk, some practitioners have created an alert system within their medical software (eg, 'cannot read', 'unemployed', 'does not have complementary health insurance'). This would be considered as 'red flags' and make practitioners be more vigilant in future consultations. Some GPs recommend to systematically collect social data in medical records for all patients, and to track social changes over time. Other GPs did not share the same opinion and proposed a progressive collection of social information over time. Two GPs recommend to care for patients with a scale and intensity that is proportionate to the level of disadvantage (referring to 'proportionate universalism').

Many practitioners highlighted the need for a full and systematic involvement of the practitioner in prevention and detection actions for all patients, since the social gradient is of great importance in preventive care.

Interviewee 10: "I will ask if he has open rights, whether he has social security, whether he has a mutual health insurance or not. I will add to the file [...] his profession, his couple situation, (...). We know that it reflects their social situation and that if they don't have coverage, they are necessarily more at risk".

Other actions suggested were optimising the communication methods with patients. Many practitioners stated 
that they called their patients to ensure proper follow-up. GPs often adapt their language with patients, using simple terms, written documents, drawings, conducting consultations in English, Italian and so on, within their possibilities. Some GPs call on translators on a regular basis (family member of the patient), or use the Internet (free translation software) or paid translation services over the phone (one GP).

Interviewee 1: "When I refer them to a specialist, I don't only give them the letter: often, I help them make an appointment, I call to make an appointment".

They also tried to prescribe medications which were $100 \%$ covered by the French social security (free from tax for patients). Many GPs also reported that they already treated patients on credit, taking into account the patients' requests regarding payment terms. Some practitioners check whether their patients benefit from the rights they are entitled to, and sometimes write medical certificates on the possible link between their social context and their health status (eg, mould and asthma for children, exposure to lead and development disorders). Finally, they recommended a specific training on this topic.

Strategies for organisational adaptation of the practitioner's office Organisational approaches include actions to promote access to healthcare (office hours, follow-up on treatment, consultation without appointment, posting of written information and pamphlets in the waiting room). Two of the GPs surveyed had decided to increase the frequency and the average duration of appointments in order to enhance the quality of care (eg, 15-20 min per consultation). As for remuneration, three GPs recommend to create French pay-for-performance indicators, taking into account the patients' social vulnerability (financial incentive for GPs based on the social context of medical practice). Many practitioners also noted the importance of multidisciplinary consultative meetings of health professionals to tackle complex bio-physical-social and cultural cases, as well as the importance of establishing multidisciplinary protocols for medical offices and for GPs who practice in other environments (patients in migrant hostels, in institutions, etc). Moreover, many GPs underlined the need for practitioners to have a network of specialist colleagues who do not charge higher consultation rates (exceeding the fixed rates). One of them uses telemedicine to facilitate access to care in a rural area (for dermatological questions).

Focus 2: We have a wide range of consultation hours [...]. Every morning, we offer 2 hours for consultation without any previous appointment. All patients, even if they don't know how to take a phone or send an email, can see a GP whenever they need it.

GPs also pointed out actions aiming at facilitating the care channel of patients (medical practice in group, including multidisciplinary healthcare homes, centres and groupings). Introducing medical students in GP offices might as well enhance the supply of healthcare and decline the cases of patients giving up on treatment. Furthermore, some of the GPs interviewed suggested to subject GP offices to quality measures to monitor health equity (which can be part of the continuous professional development).

Interviewee 2: In the future, we could monitor the evolution over time of average glycated haemoglobin in patients with diabetes based on their "professional category' $[. .$.$] . It could be a quality indicator of practice!$

\section{Community adaptation strategies}

Community approaches included a description of the health status, characteristics and healthcare needs of the GP's patients in view of adapting the treatment in the office to the place of practice.

Focus 1: First of all, we have to really know the health of our patients: Who are they? How old are they? What are their health needs? How can I adapt to their needs, me and my team? [...] Recruiting a social worker in our group, a gynaecologist, or a cardiologist?

It also consisted of informing patients on other health resources available in the area beyond healthcare (specific associations and associative activities in the vicinity, the social sector, or key resource persons in the community). Such actions by primary care professionals were also associated to work with other actors of the public health sector in the city as well as with elected officials, in order to ensure that 'micro', 'meso' and 'macro' issues were combined.

These adaptation strategies have had both positive and negative impacts on GPs and their medical practice. First, it is often noted that taking into account the social status of a patient gives the GP a feeling of personal fulfilment and achievement. GPs appreciate being able to receive the patient and follow-up his case fully, and feel useful and effective. However, the case-by-case solutions provided by GPs are also considered to put constraints on them. They sometimes feel helpless and forced to deal with unsustainable situations. Moreover, one of the recurring subjects in interviews was time management. Indeed, dedicating time for administrative matters and adapting their practice to the social status of patients result in difficulties for GPs to manage their office. Finally, some participants raised ethical questions by specifically collecting social data into medical records. They recommend to ask patients about potential social challenges in a sensitive and culturally acceptable way.

Interviewee 18: Are we not likely to stigmatise and carry out socially discriminating practices by recommending that all health professionals collect social data of their patients?

\section{DISCUSSION}

\section{Summary of results}

Social context of a patient included four main components: housing situation; income and employment; family dynamics and social supports; access and quality of health 
and social care. There were three profiles of doctors from the most sensitised to the least sensitised to social inequalities of health. This study identified adaptations at three levels: in the individual management of patients, in the collective management of patients in an office, and in the community management. Although such adaptations were recurrent in the testimonies of GPs and make them feel helpful, these adaptation strategies are too often also viewed as constraints. Ambivalence toward patients with difficult social situations has also been found at this level.

\section{Strengths and limitations of the study}

To our knowledge, this is the first French qualitative study to explore GPs perspectives on actions to take into account the social difficulties of patients in consultation. Our aim was to select physicians with different profiles, able to implement different coping strategies: some simple, others more complex. The data obtained has improved our understanding of the management of patients with social difficulties in primary care in France. The individual interviews helped collect information on sensitive matters and the dynamics of the focus group resulted in relevant discussions. Our study also has limitations. The social context is a complex concept that can result from a set of primary factors: economic, housing, physical, familial, cultural and so on. This concept has not been defined in the interview guide in order to better explore GPs representations. The GPs reported having a maximum of $40 \%$ of their patients in social difficulties in our study. Then, three GPs adapted their care only slightly and had shorter interview durations (described as 'not sensitised'). It is possible that the sample was not representative of all French GPs (especially doctors with a majority of patients with social difficulties). During the interview, GPs tended to focus on situations of extreme deprivation. The role of the investigators was to broaden the discussion to include all social vulnerabilities. Furthermore, the snowball sampling technique may have led to sampling of participants with similar views. The use of purposive sampling helped to strengthen validity and generalisation. Moreover, it would have been interesting to interview GPs practising outside the Paris region, as well as practitioners in other sectors of primary care (such as nurses, gynaecologists), social or associative specialists, and also patients in order to have a broader overview of the possibilities of future actions.

\section{Comparison with existing literature}

In our study, GPs suggested four key components to explore the social context of patients in consultation. These dimensions share interesting common elements with the Complexity Framework and its five health dimensions: social capital, demographics, health and social experiences, medical/physical health and mental health. ${ }^{28}$ In the USA, the Institute of Medicine recently suggested 11 core domains to capture social and behavioural domains in electronic health records: social connections and social isolation, stress, physical activity, intimate partner violence, financial resource strain, education, depression, census tract-median income, tobacco use and exposure, residential address, race, ethnicity and alcohol use. ${ }^{29}$ The Canadian Institute for Health Information also developed a set of priority data elements to include in electronic health records including sex, level of education, native language and housing situation. ${ }^{30}$ In a recent Canadian study, health workers with specific ways of asking patients about their social challenges (CLEAR Toolkit) were more likely to report having helped their patients as compared with those who did not know how to ask. ${ }^{31}$ In 2014, French recommendations have been published to explore the social context of patients in general practice. Seven indicators have been proposed including age, sex, address, type of social insurance, profession and ability to read. ${ }^{26}$ These recommendations are currently under revision.

Numerous actions could be used by clinicians to address social determinants in their clinical practice, in order to improve patient health and reduce social inequities in health. In our study, missed opportunities for prevention and inequitable access to care have been identified as factors leading to inefficiencies in the health system. ${ }^{28}$ Leaders in English, Canadian or American healthcare increasingly recognise the need for a social determinant and population health approach 'in reducing healthcare demand and contributing to health system sustainability'. ${ }^{32}$ The National Academy of Medicine also recommends tracking and addressing the community context of patients to improve equity and reduce health and healthcare disparities. Few studies have described the proposed actions for GPs in France. ${ }^{21-25}$ Some authors found similar results to our study concerning the collection of the social situation of the patients, the adaptation of the communication, the focus on prevention, the medical waiting room, or the medical appointments by Internet. ${ }^{21}{ }^{25} 33-36$ In addition, this report suggested new key themes to tackle health inequalities, adapted from the specific French context (consultation without appointment, medical students, telemedicine, financial adaptations, counselling in social rights, etc). In our study, the presence of a medical student at the practice was presented as helpful to tackle social inequality in health. To our knowledge, this result has not been described in the literature but seems interesting. Medical students could sometimes improve access to care (by offering new consultations), or quality of care (spending more time with the patient). Other suggested initiatives remain exceptional in the French context of general practice, or reserved to experiments supported by a specific funding (GPs paying for translation). In 2017, the French Health Insurance created 'complex consultations' with more time dedicated to patients and higher remuneration for all family physicians (eg, childhood obesity, contraception). This dedicated time could help integrate SDH more effectively.

Several authors suggested that a tension remains to know if the majority of GP(s) are equipped or motivated to do these adaptations. ${ }^{10}$ Our study also showed an 
ambivalence of GPs to take care of patients with social difficulties. To go further, some physicians probably do not want to take into account the social difficulties of patients. Two recent studies showed that they might even have discriminatory and stigmatising practices. ${ }^{34} 37$ Further studies are needed to assess the feasibility of the proposed actions and the acceptance by all French GPs. The different adaptations could be studied according to the sociodemographic characteristics of the GPs. Finally, interventional studies are needed to evaluate the impact of these actions to reduce social inequalities in health.

\section{CONCLUSION}

This study shows that GPs currently adapt their practices in a personal and intuitive way. This is certainly a first step, but not enough to improve the management of health social inequalities. To be effective, we propose three areas of actions. First, basic training and continuous medical education are needed to improve GPs' knowledge of the health system and the social resources associated. Second, we recommend standardising the collection of SDH data into electronic health records in order to better incorporate such data into clinical decision making ('the right data in the right place', and collect 'at the right time'). Finally, we recommend to deploy new care management strategies for the three levels of prevention, on professional time constraints (including task shifting, and multidisciplinary protocols). The French 2016 law of modernisation of the health system supports the expansion of primary care networks. This should be reinforced by professional recommendations to facilitate partnership with communities, patients and public health professionals.

\section{Key points}

Several studies have shown the role of the primary care system in access to care and in reducing social inequalities in health. How can French general practitioners adapt their care to patients with social difficulties?

- Our study showed that for GPs, social context of a patient could include four main components: housing situation; income and employment; family dynamics and social supports; access and quality of health and social care. We identified adaptations at three levels: in the individual management of patients, in the collective management of patients in an office, and in the community management.

- In France, general practitioners can take into account the social determinants of health through simple or more complex actions. These results may help to structure the future national recommendations.

Contributors JC, ADO, BC, MS: conceptualised and designed the study. ADO, MD, $\mathrm{Gl}$, JC: supervised the data capture and analysis. ADO, MD, Gl, JC: analysed and interpreted the data. $\mathrm{ADO}, \mathrm{BC}, \mathrm{MS}, \mathrm{MD}, \mathrm{JC}, \mathrm{Gl}$ : drafted and critically revised the manuscript. All of the authors read and approved the final manuscript.

Funding The authors have not declared a specific grant for this research from any funding agency in the public, commercial or not-for-profit sectors.

Competing interests None declared.

Patient consent for publication Not required.
Provenance and peer review Not commissioned; externally peer reviewed.

Data availability statement Data are available upon reasonable request.

Open access This is an open access article distributed in accordance with the Creative Commons Attribution Non Commercial (CC BY-NC 4.0) license, which permits others to distribute, remix, adapt, build upon this work non-commercially, and license their derivative works on different terms, provided the original work is properly cited, appropriate credit is given, any changes made indicated, and the use is non-commercial. See: http://creativecommons.org/licenses/by-nc/4.0/.

\section{ORCID iD}

Gladys Ibanez http://orcid.org/0000-0002-5592-699X

\section{REFERENCES}

1. Marmot M, Bell R. Social inequalities in health: a proper concern of epidemiology. Ann Epidemiol 2016;26:238-40.

2. Marmot M, Friel S, Bell R, et al. Closing the gap in a generation: health equity through action on the social determinants of health. The Lancet 2008;372:1661-9.

3. Ward PR. The relevance of equity in health care for primary care: creating and sustaining a 'fair go, for a fair innings'. Qual Prim Care 2009;17:49-54.

4. Stange KC, Ferrer RL. The paradox of primary care. Ann Fam Med 2009;7:293-9.

5. CORDIS, European Commission. Final Report Summary QUALICOPC (Quality and costs of primary care in Europe). Luxembourg, 2019, 2019. Available: https://cordis.europa.eu/project/ rcn/103890/reporting/en [Accessed July 2019]

6. Starfield B. Primary care and equity in health: the importance to effectiveness and equity of responsiveness to peoples' needs. Humanity Soc 2009;33:56-73.

7. Health evidence network (hen). what are the advantages and disadvantages of restructuring a health care system to be more focused on primary care services? WHO/Europe, 2004 Geneva, WHO 2004 http://www.euro.who.int/en/health-topics/ Health-systems/primary-health-care/publications/pre-2009/ what-are-the-advantages-and-disadvantages-of-restructuring-ahealth-care-system-to-be-more-focused-on-primary-care-serviceswhoeurope-2004 (accessed July 2019)

8. European Commission. Healthcare activities statistics consultations. Available: https://ec.europa.eu/eurostat/statisticsexplained/index.php?title=Healthcare_activities_statistics_-consultations\&oldid=420483 [Accessed July 2019].

9. Andermann A. Screening for social determinants of health in clinical care: moving from the margins to the mainstream. Public Health Rev 2018;39:19.

10. Hutt $P$, Gilmour S. Tackling inequalities in general practice. An inquiry into the quality of general practice in England. London, The King's fund 2010 https://www.kingsfund.org.uk/projects/gp-inquiry/healthinequalities

11. Andermann A, Collaboration C. Taking action on the social determinants of health in clinical practice: a framework for health professionals. Can Med Assoc J 2016;188:E474-E483.

12. Angier $\mathrm{H}$, Jacobs $\mathrm{EA}$, Huguet $\mathrm{N}$, et al. Progress towards using community context with clinical data in primary care. Fam Med Community Health 2019;7:e000028.

13. Husk K, Elston J, Gradinger F, et al. Social prescribing: where is the evidence? Br J Gen Pract 2019;69:6-7.

14. Brandling J, House W. Social prescribing in general practice: adding meaning to medicine. Br J Gen Pract 2009;59:454-6.

15. DeVoe JE, Bazemore AW, Cottrell EK, et al. Perspectives in primary care: a conceptual framework and path for integrating social determinants of health into primary care practice. The Annals of Family Medicine 2016;14:104-8.

16. Allen LN, Barry E, Gilbert $C$, et al. How to move from managing sick individuals to creating healthy communities. Br J Gen Pract 2019;69:8-9.

17. Balaj M, McNamara CL, Eikemo TA, et al. The social determinants of inequalities in self-reported health in Europe: findings from the European social survey (2014) special module on the social determinants of health. Eur J Public Health 2017;27(suppl_1):107-14

18. Mackenbach JP. The persistence of health inequalities in modern welfare states: the explanation of a paradox. Soc Sci Med 2012;75:761-9

19. Pubert M, Giraud J, Pisarik J, et al. Prise en charge des patients en situation de vulnérabilité sociale : opinions et pratiques des médecins généralistes. DREES. Études et Résultats 2018;1089:1-8. 
20. Flye Sainte Marie C, Querrioux I, Baumann C, et al. Difficultés des Médecins généralistes dans La prise en charge de LeuRS patients précaires. Santé Publique 2015;27:679-90.

21. Casanova L, Ringa V, Bloy G, et al. Factors associated with GPs' knowledge of their patients' socio-economic circumstances: a multilevel analysis. Fam Pract 2015;32:652-8.

22. Chatelard $\mathrm{S}$, Vaucher $\mathrm{P}$, Wolff $\mathrm{H}$, et al. [General practitioners facing social inequalities in health: which power to act?]. Rev Med Suisse 2012;8:1061--2. 4-6.

23. Flores $P$, Falcoff $H$. Peut-on agir en médecine générale sur les inégalités sociales de santé? Rev Prat 2004;54:2263-70.

24. Falcoff $H$. Que peuvent faire les médecins généralistes face aux inégalités sociales de santé ? ADSP 2010;73:41-3.

25. Chatelard S, Bodenmann P, Vaucher P, et al. General practitioners can evaluate the material, social and health dimensions of patient social status. PLoS One 2014;9:e84828.

26. French College of General Practitioners. How to collect social data during consultations? Paris, 2014. Available: http://www.lecmg.fr/ internet/index.php [Accessed July 2019].

27. Lemaire F. [The Jardé law: What does change]. Presse Med 2019;48:238-42.

28. Schaink AK, Kuluski K, Lyons RF, et al. A scoping review and thematic classification of patient complexity: offering a unifying framework. J Comorb 2012;2:1-9.

29. Committee on the Recommended Social and Behavioral Domains and Measures for Electronic Health Records. Board on population health and public health practice; Institute of medicine. capturing social and behavioral domains and measures in electronic health records: phase 2. Washington (DC: National Academies Press (US), 2015. https://www.ncbi.nlm.nih.gov/books/NBK268995/. (accessed July 2019).

30. Institut Canadien d'Information sur la Santé. Norme pancanadienne provisoire relative Au contenu Du dossier médical électronique en lien avec les soins de santé primaires, version 2.0. Available: https:// secure.cihi.ca/free products/PHC EMR_ContentStandards_E.pdf [Accessed July 2019].

31. Naz A, Rosenberg E, Andersson N, et al. Health workers who ask about social determinants of health are more likely to report helping patients: mixed-methods study. Can Fam Physician 2016;62:e684-93.

32. Cohen D, Huynh T, Sebold A, et al. The population health approach : A qualitative study of conceptual and operational definitions for leaders in Canadian healthcare. SAGE Open Medicine 2014;2.

33. Ellouze S, Lafortune J, Soares A. [Predictors of online medical appointments with general practitioners]. Sante Publique 2018;30:371-82.

34. De Pauw C. Les Médecins généralistes face Au défi de la précarité. EHESP, Presses de l'EHESP, 2017.

35. Casanova L, Ringa V, Chatelard S, et al. Level of agreement between physician and patient assessment of non-medical health factors. Fam Pract 2018;35:488-94.

36. Bodenmann $\mathrm{P}$, Wolff $\mathrm{H}$, Bischoff $\mathrm{T}$, et al. [Patients forgoing health care for economic reasons: how to identify this in a primary care setting?]. Rev Med Suisse 2014;10:2258-60.

37. Cognet M, Gabarro C, Adam-Vezina E. Entre droit aux soins et qualité des soins. Hommes et migrations 2009;1282:54-65. 